\title{
ARTIGOS
}

Submetido em 07.09.2019. Aprovado em 17.03.2020

Avaliado por meio de double blind-review. Editor Científico convidado: Andre Silva

Versão traduzida

DOI: http://dx.doi.org/10.1590/So034-759020200405

\section{ADOÇÃO OBRIGATÓRIA DE IFRS, GOVERNANÇA CORPORATIVA EVALOR DA FIRMA}

\author{
Mandatory IFRS adoption, corporate governance, and firm value \\ Adopción obligatoria de las NIIF, gobierno corporativo y valor de firma
}

\section{JOELSON SAMPAIO ${ }^{1}$}

joelson.sampaio@fgv.br

ORCID: 0000-0001-6560-2481

\section{HUMBERTO GALLUCCI² \\ humberto.gallucci@unifesp.br \\ ORCID: 000-0001-7905-1879}

\section{VINICIUS AUGUSTO BRUNASSI SILVA ${ }^{3}$}

vinicius.brunassi@fecap.br

ORCID: 0000-0002-1299-321X

\section{RAFAEL FELIPE SCHIOZER ${ }^{4}$ \\ rafael.schiozer@fgv.br \\ ORCID: 0000-0003-3890-6345}

1 Fundação Getulio Vargas, Escola de Economia de São Paulo, São Paulo, SP, Brasil

2 Universidade Federal de São Paulo, Departamento de Ciências Atuariais, São Paulo, SP, Brasil

${ }^{3}$ Fundação Escola de Comercio Álvares Penteado, Instituto de Finanças, São Paulo, SP, Brasil

4Fundação Getulio Vargas, Escola de Administração de Empresas de São Paulo, São Paulo, SP, Brasil

\section{RESUMO}

Estudamos se o nível de divulgação contábil e financeiro afeta o valor da firma, focando a adoção do padrão IFRS no Brasil em 2010. Comparamos firmas com pior qualidade contábil ex-ante (no nível regular e nível 1 de governança corporativa) com firmas similares que já adotavam o IFRS antes de se tornar mandatório (Nível 2 e Novo Mercado). Encontramos que a adoção do IFRS tem um impacto positivo de aproximadamente 30 pontos percentuais no $Q$ de Tobin e 26 pontos percentuais na razão entre valor de mercado e valor patrimonial para firmas nos níveis mais baixos de governança, e reduz substancialmente a diferença de valuation entre firmas nos níveis altos e baixos de governança corporativa. Essa redução na diferença de valuation é parcialmente explicada pelo aumento relativo na participação de estrangeiros no capital acionário e na liquidez das ações das firmas nos níveis mais baixos de governança corporativa.

PALAVRAS-CHAVE | IFRS, governança corporativa, valor da firma, qualidade contábil, assimetria informacional.

\section{ABSTRACT}

We studied whether the level of financial and accounting disclosure affects the firm's value by focusing on the adoption of International Financial Reporting Standards (IFRS) in Brazil in 2010. We compared firms with worse ex-ante accounting quality (Regular and Level 1 tiers of corporate governance) with similar firms that had already adopted IFRS before it became mandatory (Level 2 and Novo Mercado tiers). We found the IFRS adoption has a positive impact of approximately 30 percentage points on Tobin's $Q$ and 26 percentage points on market-to-book ratios for firms in the lower governance tiers, and substantially reduces the valuation gap between firms in the higher and lower tiers of corporate governance. This reduction in the valuation gap after IFRS adoption is partly explained by the relative increase in foreign ownership and stock liquidity of firms in the lower governance tiers.

KEYWORDS / IFRS, corporate governance, firm value, accounting quality, information asymmetry.

\section{RESUMEN}

Estudiamos si el nivel de la divulgación de información financiera y contable afecta el valor de la empresa, considerando la implementación en Brasil de las Normas Internacionales de Información Financiera (NIIF) en 2010. Comparamos las empresas con una contabilidad de menor calidad (empresas en el Nivel Regular y Nivel 1 de gobierno corporativo) con empresas similares que ya había adoptado las NIIF antes de que fuera obligatorio (Nivel 2 y Novo Mercado). Encontramos que la adopción de las NIIF tiene un impacto positivo de aproximadamente 30 puntos porcentuales en la Q de Tobin y 26 puntos porcentuales en la relación entre el valor de mercado y el valor de capital para las empresas en los niveles más bajos de gobierno, y reduce sustancialmente la diferencia de valoración entre empresas en los niveles más altos y más bajos de gobierno corporativo. Esta reducción en la diferencia de valoración después de la adopción de las NIIF se explica en parte por el aumento relativo en la propiedad extranjera y la liquidez de las acciones de las empresas en los niveles más bajos de gobierno corporativo.

PALABRAS CLAVE I IFRS, Gobierno corporativo, valor de la empresa, cualidad contabilidad, asimetría de la información. 


\section{INTRODUÇÃO}

O padrão IFRS tornou-se obrigatório para todas as firmas brasileiras em 2010. Comparamos os efeitos heterogêneos de sua adoção em firmas com padrões baixos e elevados de governança corporativa ex-ante e concluímos que o IFRS diminuiu a diferença de valuation preexistente entre os dois tipos de firma.

Numerosos estudos enfocaram as consequências econômicas do aumento dos níveis de disclosure financeira das firmas. Em particular, a adoção do IFRS pela União Europeia (UE) em 2005 tornou-se uma área popular de pesquisa (ver George, Li e Shivakumar (2016) para uma revisão aprofundada dos estudos de adoção do (FRS). No entanto, os benefícios do IFRS podem não estar totalmente avaliados, pois a maioria dos estudos examinou os efeitos de sua adoção em países onde 0 ambiente informacional existente já era rico. Além disso, a UE exigiu aprovação prévia por parte da Comissão Europeia para quaisquer alterações nos padrões de relatórios a ser obrigatoriamente aplicados. Isso resultou em uma adoção fragmentada do IFRS (KPMG, 2008) na UE; portanto, mudanças no ambiente de disclosure financeiro das firmas europeias após 2005 não capturam completamente os benefícios da adoção do IFRS.

O foco no Brasil ajuda na identificação empírica por vários motivos. Primeiro, o IFRS representa uma melhoria substancial nos padrões contábeis em relação aos princípios contábeis anteriormente aceitos como regra geral no Brasil (BRGAAP). Como o sistema jurídico brasileiro é derivado da tradição do direito codificado, o BRGAAP era fortemente influenciado pela legislação tributária, e favorecia a forma sobre a essência. Comparado ao BRGAAP, o IFRS melhorou as informações disponiveis aos investidores estrangeiros ao proporcionar maior transparência e padrões contábeis unificadores. A adoção do IFRS foi promulgada pela Lei 11.638 de 2007 , e foi implementada em um tempo relativamente curto em comparação com outras jurisdições. A lei foi aprovada em dezembro de 2007, e foi seguida de um "período híbrido" (2008 e 2009), durante o qual as práticas contábeis convergiram gradualmente para o IFRS (Pelucio-Grecco, Geron, Grecco, e Lima, 2014). Finalmente, a implementação completa foi concluída no primeiro trimestre de 2010.

Em segundo lugar, o Brasil oferece um conjunto de firmas com qualidade contábil ex-ante heterogênea. Antes da adoção geral do IFRS no Brasil, as firmas nos níveis mais altos de governança corporativa da Bolsa de Valores de São Paulo (Novo Mercado e Nivel 2) tinham melhor disclosure do que as firmas nos níveis mais baixos. Portanto, a adoção do IFRS resultou em um maior grau de melhoria na transparência e disclosure para firmas nos níveis baixos do que para aquelas situadas nos níveis mais altos. Essas duas características proporcionam variação na qualidade contábil, tanto transversalmente (ou seja, entre firmas), quanto ao longo do tempo, permitindo uma melhor estratégia de identificação empírica. Finalmente, o foco em um único país elimina diferenças micro e macroeconômicas entre países, as quais poderiam confundir a identificação empírica.

Padrões uniformes como o IFRS reduzem a assimetria informacional. Analisamos a eficácia desses padrões, estudando a diminuição da discrepância de valor existente entre as firmas listadas no Brasil sob diferentes requisitos de governança corporativa antes da adoção do IFRS. Em 2000, a Bolsa de Valores de São Paulo criou três níveis especiais de listagem de governança (Nível 1, Nível 2 e Novo Mercado) para melhorar as práticas de governança e estabelecer uma diferenciação entre as firmas listadas nos níveis especiais de governança e as firmas listadas regulares. As firmas listadas no Novo Mercado apresentam os mais altos padrões de governança corporativa, enquanto as firmas listadas no Nível 2 possuem a maior parte dos requisitos do Novo Mercado, exceto pelo fato de poderem ter ações sem direito a voto. Todas as firmas de Nível 2 e Novo Mercado foram obrigadas a utilizar o IAS/IFRS a partir de 2000. As firmas listadas no Nível 1 e no nível Regular não estavam sujeitas a esse requisito obrigatório, e puderam usar o BRGAAP até 2007.

A aprovação da lei em 2007 exigiu que todas as firmas de capital aberto adotassem o IFRS, mas essa mudança afetou apenas as práticas contábeis exigidas para as firmas de nível 1 e nível regular (doravante denominadas "tratadas"), porque as firmas do Novo Mercado e do nível 2 (firmas "não tratadas") já haviam adotado o IFRS. Portanto, essa lei oferece um desenho de experimento quase natural: proporcionando uma fonte de variação de disclosure heterogênea entre as firmas e quase exógena.

Nossos resultados mostram que a adoção obrigatória do IFRS tem um impacto positivo no $Q$ de Tobin e na razão entre valor de mercado e valor patrimonial para firmas com pior qualidade de divulgação ex-ante. Como sugerem os gráficos 1 e 2, a implementação do IFRS elimina quase completamente a diferença de valuation preexistente $(Q$ de Tobin e razão entre valor de mercado e valor patrimonial) entre as firmas nos níveis mais baixos e mais altos de governança corporativa. Nossos testes confirmam que a redução diferencial no $Q$ de Tobin e na razão entre valor de mercado e valor patrimonial é estatisticamente significativa, com magnitudes de 30 e 26 pontos percentuais, respectivamente (correspondendo a aproximadamente $20 \%$ das medidas pré-choque dessas variáveis). Esse resultado é consistente com o de Black, Carvalho, Khanna, Kim e Yurtoglu (2017), que constataram que o aumento de um desvio padrão no nível de disclosure prevê um aumento de $19 \%$ no Q de Tobin. Nossos estimadores de pareamento (matching) garantem 
que a comparação é feita entre firmas tratadas e não tratadas que são semelhantes em termos de características observáveis, como setor, tamanho e alavancagem.

\section{Gráfico 1. Q de Tobin mediano}

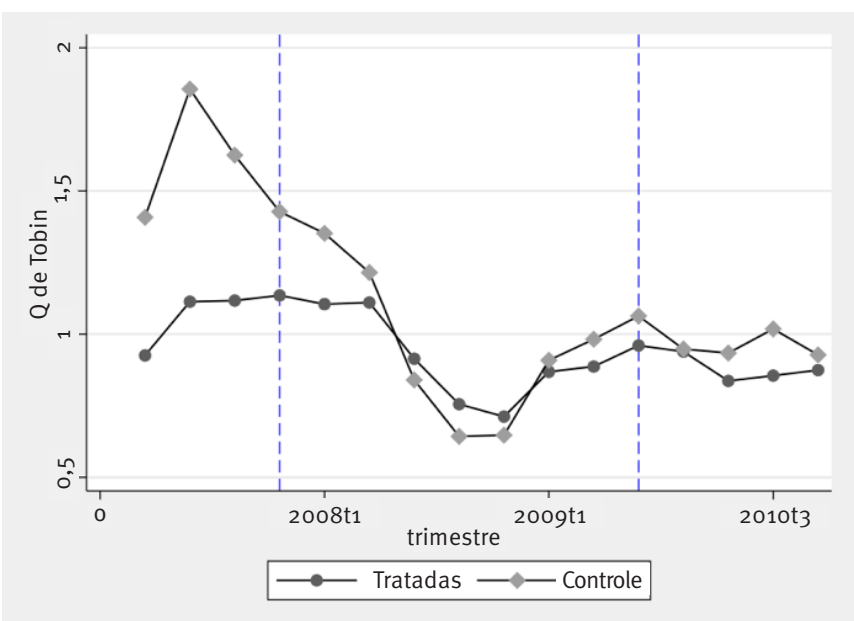

Nota: Mediana de trimestre para cada grupo. O Q de Tobin é winsorizado no nível de $5 \%$. Tratadas são firmas do nível Regular e Nível 1 de governança; Controle são firmas do Nível 2 e Novo Mercado de governança. A amostra compreende 76 firmas tratadas e 76 do grupo de controle.

\section{Gráfico 2. Razão entre valor de mercado e valor patrimonial mediana}

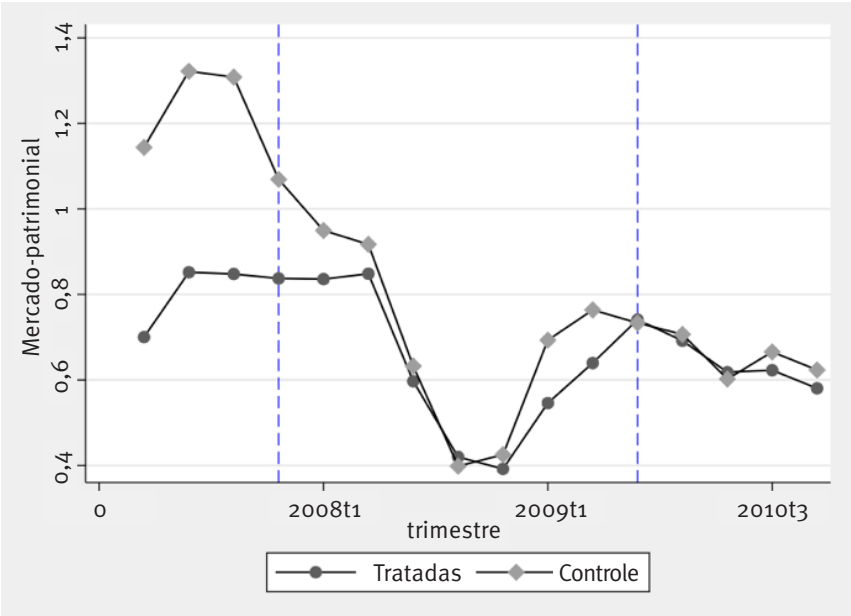

Nota: Mediana de trimestre para cada grupo. A razão entre valor de mercado e valor patrimonial é winsorizada no nível de $5 \%$. Tratadas são firmas do nível Regular e Nível 1 de governança; Controle são firmas do Nível 2 e Novo Mercado de governança. A amostra compreende 76 firmas tratadas e 76 do grupo de controle.

Também apresentamos evidências sobre o mecanismo que leva à diminuição da diferença de valuation entre as firmas tratadas e não tratadas após a adoção do IFRS. Primeiro, mostramos que a diferença na participação de investidores estrangeiros no capital acionário entre as firmas tratadas e não tratadas é significativamente reduzida após a adoção do IFRS. Nenova (2003) aponta os baixos padrões contábeis como uma das fragilidades que inibem os investimentos estrangeiros no Brasil. A adoção do IFRS oferece um conjunto de padrões que permite aos investidores estrangeiros adquirir informações com mais eficiência (Amiram, 2012). Em segundo lugar, verificamos que a diferença na liquidez das ações também diminui após a adoção do IFRS.

Essas duas evidências são consistentes com a noção de que os acionistas controladores das firmas tratadas (de baixa qualidade de governança) eram desincentivados a migrar para o IFRS antes de sua adoção obrigatória porque podiam obter benefícios de controle privado utilizando o BRGAAP. Portanto, a menor diferença de valuation entre as firmas tratadas e não tratadas após a adoção do IFRS está possivelmente relacionada à redução do poder dos acionistas controladores de expropriar acionistas minoritários e detentores de títulos de dívida. Portanto, nossa pesquisa contribui para a literatura que associa o aumento dos níveis de disclosure contábil à diminuição da expropriação por acionistas controladores.

Este estudo contribui, no mínimo, de duas formas para a literatura existente. Em primeiro lugar, é o primeiro estudo a investigar a interação entre governança corporativa, transparência contábil e valuation da firma em um contexto de mercado emergente. Embora vários autores tenham examinado o efeito da contabilidade sobre o valuation em economias desenvolvidas (Armstrong, Barth e Riedl, 2010; Daske, Hail, Leuz e Verdi, 2008), e a relação entre governança corporativa e qualidade e transparência contábil (Verrecchia, 2001; Verriest, Gaereminck e Thornton, 2012), este é o primeiro estudo a interligar esses três aspectos em um desenho de experimento quase natural em uma economia emergente. Em segundo lugar, em comparação com trabalhos anteriores sobre o tema, as características do mercado brasileiro (adoção total do IFRS e heterogeneidade da qualidade contábil ex-ante) oferecem uma melhor estratégia de identificação empírica para avaliar os efeitos da transparência contábil no valor da firma.

Nossas inferências resistem a vários testes de robustez. Uma preocupação em potencial em nossa estratégia empírica é que o período de adoção do IFRS (2008 a 2010) coincide parcialmente com a crise financeira. Se a atribuição do tratamento estiver correlacionada a variáveis macroeconômicas afetadas pela crise e importantes para o valuation da firma (por exemplo, se firmas com melhor governança corporativa estiverem mais expostas a choques no setor financeiro), o efeito observado no valuation seria erroneamente atribuído ao IFRS. Abordamos 
essa preocupação verificando se as métricas operacionais e financeiras (lucros, receita e alavancagem) foram afetadas pela crise de forma diferente para as firmas tratadas e não tratadas, e não encontramos diferenças significativas entre os dois grupos. Como o Real sofreu uma depreciação de $30 \%$ logo após a quebra do Lehman Brothers, utilizamos também um teste placebo para verificar se as firmas dos dois grupos tinham exposição diferente a moedas estrangeiras, e não encontramos evidências de diferença. Além disso, incluímos controles em nossas estimativas para uma série de variáveis que a literatura constatou afetarem o valuation da firma. Nossos resultados são consistentes com a literatura anterior.

Outra possível preocupação em nossa estratégia de identificação é que, antes da adoção obrigatória do IFRS, as firmas podem ter se auto selecionado entre os grupos de tratamento e controle; como as firmas podiam optar por cumprir os requisitos do segmento Novo Mercado ou Nível 2, a atribuição do tratamento pode não ser aleatória. Nosso procedimento de pareamento garante que as firmas que comparamos nos grupos tratado e de controle são similares nos demais aspectos.

0 restante do artigo está organizado conforme segue. A segunda seção situa nossa contribuição no contexto da literatura relacionada e descreve o cenário institucional brasileiro. A terceira seção fornece detalhes sobre os dados, enquanto a quarta seção explica nossa estratégia de identificação. A quinta seção apresenta os resultados, e a sexta seção discute o mecanismo por trás da mudança na diferença de valuation e uma série de testes de robustez. A última seção conclui o trabalho.

\section{LITERATURA RELACIONADA}

Este estudo relaciona-se mais estreitamente com os estudos "baseados em associação" na literatura financeira sobre disclosure, que geralmente buscam documentar os efeitos da redução da assimetria informacional sobre o volume de negociações, a liquidez das ações e o valor da firma (Kanodia, 2006). Pesquisas teóricas e empíricas anteriores sugerem uma relação negativa entre assimetria informacional, volume de negociações e liquidez das ações (Admati \& Pfleiderer, 1988). Por exemplo, Leuz e Verrecchia (2000) consideraram o compromisso voluntário de aumentar os níveis de disclosure na Alemanha. Eles verificaram aumentos no volume de negociações para firmas que migraram do GAAP alemão para o IAS ou o US GAAP, sugerindo que a disclosure diminui o componente de assimetria informacional do custo do capital. Da mesma forma, Beatty, Chamberlain e Magliolo (1996) constataram que melhorias na qualidade contábil estão associadas a menores custos de contratação e a uma menor extração gerencial de renda.

Pesquisas anteriores ilustram os benefícios de níveis mais elevados de qualidade de relatórios financeiros. Em geral, as melhorias na qualidade contábil estão relacionadas a um menor custo do capital e a retornos anormais positivos (Baiman \& Verrecchia, 1996; Barth, Konchitchki \& Landsman, 2013; Daske, Hail, Leuz, \& Verdi, 2013; Diamond \& Verrecchia, 1991; Karamanou \& Nishiotis, 2005; Leuz \& Verrecchia, 2000). Botosan e Plumlee (2002) destacaram que o custo de capital implícito da firma está negativamente relacionado a melhores práticas de governança, e Charitou, Karamanou e Kopita (2018) constataram que as recomendações dos analistas a respeito de ações tornaram-se mais informativas após a adoção do IFRS.

Daske et al. (2008) avaliaram as consequências econômicas da adoção obrigatória do IFRS em um cenário internacional. Eles mostraram que a liquidez do mercado, o valuation do patrimônio e o custo do capital melhoraram após a adoção do IFRS (a liquidez do mercado e o valuation do patrimônio aumentaram, enquanto o custo do capital diminuiu). Lepone e Wong (2018) constataram que a adoção do IFRS reduziu o bid-ask spread de ações australianas, e Charoenwong, Chong e Wang (2014) mostraram que a relação entre liquidez de ativos e liquidez de ações foi reduzida devido à maior transparência após a adoção do IFRS.

Segundo Coffee (1984), Dye (1990) e Lambert, Leuz e Verrecchia (2007), os investidores podem comparar melhor as firmas em nível internacional devido às práticas de relatórios do IFRS. Além disso, Verrecchia (2001) e Lambert et al. (2007) constataram que relatórios financeiros de melhor qualidade e uma melhor disclosure ajudaram a mitigar problemas adversos de seleção.

Apesar das melhorias proporcionadas pelas melhores práticas de governança, Jeanjean e Stolowy (2008) observaram que o IFRS oferece condições necessárias, mas não suficientes, para a criação de uma linguagem comercial comum. Além disso, alguns pesquisadores do tema de incentivos a divulgação de informações, como Ball, Kothari e Robin (2000), Ball, Robin e Wu (2003) e Daske et al. (2008), questionam o impacto de melhores políticas de demonstrações contábeis. Santos, Schiozer e Ponte (2019) mostraram que características de país, tais como origem jurídica, aplicação da lei e análise do mercado de capitais, são determinantes importantes do nível de disclosure, mesmo anos após a implementação do IFRS.

A implementação eficaz do IFRS nos relatórios da firma também desempenha um papel importante (Armstrong et al., 2010; Ball, 2006). Daske et al. (2008) mostraram que o custo 
do capital e o Q de Tobin são afetados por alterações nas regras contábeis. Verriest et al. (2012) explicaram que, em um cenário de aumento obrigatório de disclosure, a conformidade está associada a sinais anteriores de governança de melhor qualidade.

\section{O IFRS E A GOVERNANÇA CORPORATIVA NO BRASIL - ARCABOUÇO INSTITUCIONAL}

Nosso foco em um único país, o Brasil, permite identificar melhor os efeitos do IFRS no valuation. De acordo com o BRGAAP, os recebíveis e contas a pagar eram registrados pelo valor nominal, enquanto o IFRS exige que os ativos e passivos sejam descontados a valor presente, se relevantes. Além disso, o BRGAAP não fazia distinção entre ações ordinárias (com direito a voto) e ações preferenciais (sem direito a voto). Já no caso do IFRS, uma firma deve calcular o lucro diluído por ação para as ações ordinárias, incluindo potencial diluidor (opções e instrumentos conversíveis) se elas atenderem a determinados critérios. Rodrigues, Schmidt e Dos-Santos (2012) descreveram em detalhes as mudanças devidas à adoção do IFRS, e as mudanças que tal adoção realizou no Brasil.

Autores anteriores analisaram alguns efeitos da adoção do IFRS no Brasil. Figlioli, Lemes e Lima (2017) indicaram níveis reduzidos de sincronicidade (ou seja, um aumento na proporção de informações específicas da firma que afetam os retornos) de ações negociadas após a implementação obrigatória do IFRS no Brasil, e Pelucio-Grecco et al. (2014) argumentaram que a implementação do IFRS melhora a qualidade contábil, reduzindo o gerenciamento de resultados, principalmente para firmas reguladas.

Silveira e Barros (2008) investigaram os determinantes da governança corporativa no Brasil e constataram que a concentração acionária está negativamente relacionada aos níveis de governança corporativa. Black, de Carvalho e Gorga (2010) mostraram que a bolsa de valores de São Paulo criou três níveis de listagem de melhor governança em 2000 com regras opcionais de governança que forneciam proteção adicional aos acionistas minoritários. Black, Carvalho e Sampaio (2014) mostraram que a criação dos três níveis de listagem de melhor governança melhorou significativamente os direitos dos investidores, resultando em um boom nas ofertas públicas iniciais no Brasil entre 2004 e 2008. A maioria das firmas novatas foram listadas em um dos níveis de melhor governança, enquanto algumas firmas mais antigas ajustaram procedimentos e estatutos, permitindo sua migração para níveis de melhor governança corporativa. Pesquisas anteriores também abordaram o efeito da governança corporativa no valor da firma no Brasil antes da implementação do IFRS. Silveira, Barros e Famá (2003) encontraram evidências de que as firmas têm valores mais elevados quando o CEO não é o presidente do conselho.

Nosso estudo avança nesses aspectos e especifica uma estratégia de identificação para o estudo de participações de investidores estrangeiros e melhorias na liquidez das ações após a adoção do IFRS. Ele se destaca de estudos anteriores na medida em que examinamos os efeitos da melhoria da qualidade contábil, utilizando um caso em que a melhoria é obrigatória e aplicada uniformemente em um conjunto bem definido de firmas. Utilizamos um choque quase natural e exploramos a distinção ex-ante entre os requisitos de padrões contábeis dos níveis de governança no Brasil. Essa configuração nos permite identificar os efeitos da adoção do IFRS, utilizando um grupo específico de firmas, e comparar os efeitos de padrões contábeis aprimorados no valor da firma, comparando as firmas desse grupo específico com firmas similares (isto é, pareadas) que já haviam adotado o IFRS. Seguimos Klapper e Love (2004), Durnev e Kim (2005) e Black et al. (2014) e utilizamos o Q de Tobin como proxy do valor da firma.

\section{DADOS}

Coletamos demonstrações financeiras e informações corporativas sobre firmas brasileiras de capital aberto, entre 2004 e 2015, da base de dados Economatica. Nossos principais testes utilizam dados do período de adoção do IFRS (entre 2007 e 2010), enquanto outros períodos são utilizados para testes de robustez e placebo. A Tabela 1 oferece as definições operacionais de nossas variáveis financeiras.

Coletamos manualmente os dados de propriedade acionária da Comissão de Valores Mobiliários (CVM). Analisamos o relatório de Informações Anuais (IAN) e o Formulário de Referência (FR), que trazem informações sobre a participação acionária de investidores estrangeiros para todas as firmas em todos os anos durante o período amostral. Por fim, coletamos dados de bid-ask spread (utilizados para calcular medidas de liquidez) do Capital IQ.

A tabela 2 apresenta nosso procedimento de seleção amostral. A exclusão de observações utilizou os seguintes filtros: i) firmas que mudaram de nível de governança corporativa durante o período amostral; ii) firmas estrangeiras negociadas no mercado de balcão (OTC) listadas como BDRs (Brazilian Depositary Receipts) e firmas listadas no “Bovespa Mais” (firmas semelhantes às do Novo Mercado, porém menores e com algumas restrições); iii) firmas do nível Regular ou Nível 1 com American Depositary Receipts (ADRs) e firmas com quaisquer alterações 
no status de ADR, pois tais firmas poderiam estar sujeitas a exigências mais rígidas de disclosure devido a cross-listing; iv) firmas passando por reorganização financeira; v) firmas dos setores NAICS 522, 524, 525 e 551 (empresas financeiras, de seguros e de gestão); vi) firmas com falta de informações em 2007 ou 2010. Nossa amostra final é composta por 132 firmas, sendo 56 no grupo não tratado (Novo Mercado e Nível 2) e 76 no grupo tratado (Nível 1 e nível Regular).

\section{Tabela 1. Definições das variáveis}

\begin{tabular}{l|l}
\hline Q de Tobin & $\begin{array}{l}\text { (valor contábil de dívida+ valor de } \\
\text { mercado das ações ordinárias)/valor } \\
\text { patrimonial }\end{array}$ \\
\hline Mercado-patrimonial & Valor de mercado/valor patrimonial \\
\hline In (ativos) & Logaritmo natural do valor patrimonial \\
\hline Alavancagem & (Total de dívidas)/valor patrimonial total \\
\hline Receita líquida /ativos & (Receita líquida)/valor patrimonial total \\
\hline EBIT/vendas & $\begin{array}{l}\text { (Lucro antes dos juros e impostos)/total } \\
\text { de vendas }\end{array}$ \\
\hline PPE/vendas & $\begin{array}{l}\text { (Propriedade, planta e equipamentos)/ } \\
\text { total de vendas }\end{array}$ \\
\hline EBIT/ativos & $\begin{array}{l}\text { (Lucro antes dos juros e impostos)/ valor } \\
\text { patrimonial total }\end{array}$ \\
\hline Dummies de setor & \begin{tabular}{l} 
NAICS de três dígitos \\
\hline
\end{tabular}
\end{tabular}

\section{Tabela 2. Seleção de processo e amostra}

\begin{tabular}{l|c}
\hline Número de firmas em 2007 & 444 \\
\hline Exclusão de firmas com: & \\
\hline $\begin{array}{l}\text { Mudança no nível de listagem de governança corporativa } \\
\text { entre 2007 e 2010 }\end{array}$ & 1 \\
\hline BDR e OTC & 7 \\
\hline Firmas do nível Regular ou Nível 1 com ADR & 14 \\
\hline Setores NAICS 522, 524, 525 e 551 & 59 \\
\hline Firmas passando por reorganização corporativa & 11 \\
\hline Sem informação sobre vendas & 14 \\
\hline Sem dados em 2007 e 2010 & 206 \\
\hline Total & 132 \\
\hline Firmas do Novo Mercado e Nível 2 (firmas não tratadas) & 56 \\
\hline Firmas do nível Regular e Nível 1 (firmas tratadas) & 76 \\
\hline
\end{tabular}

Nota: Seleção de processo e amostra aplicada a dados da Economatica.
Fazemos o pareamento de firmas dos grupos tratados e não tratados, com base em sua classificação de setor de 3 dígitos, tamanho e alavancagem; há 76 firmas tratadas e 76 firmas controle. Nossa amostra principal inclui informações trimestrais do primeiro trimestre de 2007 ao quarto trimestre de 2010 . Nosso procedimento de pareamento foi realizado com substituição, seguindo Roberts e Whited (2013). Portanto, uma firma não tratada poderia estar pareada a mais de uma firma tratada. Na maioria de nossos exames empíricos, utilizamos dados de 2007 (antes da adoção obrigatória do IFRS) e 2010 (após a implementação completa do IFRS). Também realizamos uma série de verificações de robustez, utilizando os períodos de 2006 a 2015.

O Painel A da Tabela 3 apresenta as estatísticas descritivas para as principais variáveis de interesse, dividindo a amostra em firmas tratadas (ou seja, firmas do nível Regular e Nível 1 de governança corporativa, que foram forçadas a adotar o IFRS após 2007) e firmas controle (firmas do Nível 2 e Novo Mercado, que já adotavam o IFRS antes de 2007). Não observamos diferenças marcantes entre as firmas tratadas e controle em relação a essas variáveis. As firmas tratadas são apenas um pouco menores do que as firmas controle, com níveis médios similares de alavancagem, receita líquida/ativos e EBIT/ativos. As firmas do grupo de controle têm níveis médios um pouco mais altos de PPE/vendas e EBIT/vendas. 0 painel $B$ da tabela 3 exibe a matriz de correlação para essas variáveis.

\section{ESTRATÉGIA DE IDENTIFICAÇÃO E PROCEDIMENTO DE PAREAMENTO}

Exploramos a distinção entre os requisitos contábeis padrão dos níveis de listagem. As firmas do Nível 2 e Novo Mercado foram obrigadas a utilizar o IAS/IFRS a partir de 2000, enquanto as firmas do nível Regular e Nível 1 utilizaram o GAAP brasileiro até 2007. A lei exigiu que todas as firmas de capital aberto adotassem o IFRS, mas, na prática, exigiu uma alteração nas demonstrações contábeis apenas para firmas do nível Regular e Nível 1 (firmas tratadas).

A seleção em níveis de governança foi originalmente realizada pelas próprias firmas, o que significa que a atribuição de grupos não é aleatória. No entanto, a auto seleção das firmas em diferentes níveis de governança corporativa parece não estar relacionada à aprovação da lei que torna o IFRS obrigatório para todas as firmas brasileiras, pois, para a maioria das firmas, a atribuição de nível foi feita sete anos antes da aprovação da lei. O longo período entre a atribuição de grupo e a aprovação da lei torna implausível a suposição de que as firmas decidiram cumprir os requisitos de nível mais alto de governança por preverem a futura adoção obrigatória do IFRS. 
ARTIGOS | ADOÇÃO OBRIGATÓRIA DE IFRS, GOVERNANÇA CORPORATIVA E VALOR DA FIRMA

Joelson Sampaio | Humberto Gallucci | Vinicius Augusto Brunassi Silva | Rafael Felipe Schiozer

Tabela 3. Estatísticas descritivas e matriz de correlação

\begin{tabular}{|c|c|c|c|c|c|}
\hline \multicolumn{6}{|c|}{ Painel A - Estatísticas Descritivas } \\
\hline Treated $(n=76)$ & Média & Mediana & Desvio padrão & Mínimo & Máximo \\
\hline In (ativos) & 14,04 & 13,88 & 1,99 & 10,46 & 17,78 \\
\hline Alavancagem & 0,25 & 0,23 & 0,14 & 0,00 & 0,61 \\
\hline Receita líquida/ativos & 0,04 & 0,04 & 0,09 & $-0,32$ & 0,20 \\
\hline EBIT/vendas & 0,15 & 0,11 & 0,23 & $-0,42$ & 0,94 \\
\hline EBIT/ativos & 0,09 & 0,08 & 0,09 & $-0,16$ & 0,27 \\
\hline \multicolumn{6}{|l|}{ Controle $(n=76)$} \\
\hline $\ln$ (ativos) & 14,60 & 14,53 & 0,99 & 12,60 & 16,74 \\
\hline Alavancagem & 0,25 & 0,23 & 0,14 & 0,00 & 0,45 \\
\hline PPE/vendas & 2,24 & 0,81 & 2,89 & 0,12 & 11,23 \\
\hline EBIT/ativos & 0,08 & 0,07 & 0,06 & $-0,05$ & 0,27 \\
\hline \multicolumn{6}{|c|}{ Painel B - Matriz de Correlação } \\
\hline & $\ln$ (ativos) & Alavancagem & Receita líquida / ativos & $\mathrm{EBIT} /$ vendas & PPE/vendas \\
\hline Alavancagem & $0,15^{*}$ & 1,00 & & & \\
\hline Receita líquida/ativos & $0,35^{\star \star *}$ & $-0,01$ & 1,00 & & \\
\hline EBIT/vendas & $0,27^{\star \star \star}$ & $0,45^{\star \star \star}$ & $0,33^{* * *}$ & 1,00 & \\
\hline PPE/vendas & 0,01 & $-0,05$ & $-0,14$ & 0,11 & 1,00 \\
\hline
\end{tabular}

Nota: Esta Tabela apresenta as estatísticas descritivas e a matriz de correlação para os grupos de tratamento e controle. Ambos os grupos têm 76 observações. 0 s símbolos *, ** $\mathrm{e}^{* * *}$ indicam significância estatística em 10\%, 5\% e 1\%, respectivamente.

Para mitigar ainda mais as preocupações com a atribuição não aleatória, seguimos Almeida, Campello, Laranjeira e Weisbenner (2011) e adotamos uma estratégia menos paramétrica mais estreitamente relacionada à noção de teste "baseado em experimento". Nessa estrutura, pareamos firmas do grupo tratado com firmas semelhantes do grupo controle, a fim de garantir que as observações tratadas e de controle pertençam ao mesmo setor e possuam características semelhantes em dimensões observáveis. Pareamos as firmas tratadas com as não tratadas, utilizando uma técnica de escore de propensão (propensity score) baseada em setor (NAICS de três dígitos), tamanho e alavancagem a partir do último trimestre de 2007. Também realizamos procedimentos alternativos de pareamento, utilizando outras covariáveis, como lucro líquido/ativos, EBIT/vendas, PPE/vendas e EBIT/ ativos. Seguimos a recomendação de Angrist e Pischke (2008) e utilizamos um modelo parcimonioso que contém apenas as covariáveis que realmente preveem o tratamento. Como existem mais firmas tratadas do que não tratadas em nossa amostra, pareamos toda firma tratada com uma única firma não tratada, seguindo Almeida et al. (2011). Também seguimos a sugestão de Roberts e Whited (2013) e utilizamos substituição em nosso procedimento de pareamento. Após o pareamento, a amostra inclui 76 firmas tratadas e 76 firmas de controle (não tratadas).

A Tabela 4 apresenta testes de comparação de medianas para nossas principais covariáveis, seguindo Almeida et al. (2011). Comparamos as firmas tratadas e controle em relação a mudanças na própria firma nas variáveis de pareamento (tamanho e alavancagem), bem como na receita líquida/ativos, EBIT/ativos, EBIT/vendas e PPE/vendas a partir do último trimestre de 2007 . Estes testes nos permitem capturar uma heterogeneidade invariante no tempo, através da comparação das mudanças na própria firma nessas variáveis. Não encontramos diferenças significativas entre os grupos tratado e de controle nas medianas variáveis, sugerindo que nosso procedimento pareou com sucesso as firmas tratadas e de controle nessas dimensões, antes da aprovação da lei. 
ARTIGOS | ADOÇÃO OBRIGATÓRIA DE IFRS, GOVERNANÇA CORPORATIVA E VALOR DA FIRMA

Joelson Sampaio | Humberto Gallucci | Vinicius Augusto Brunassi Silva | Rafael Felipe Schiozer

Tabela 4. Medianas para as firmas tratadas e controle em 2007

\begin{tabular}{l|c|c|c|c|c|c}
\hline & In (ativos) & Alavancagem & Receita líquida /ativos & EBIT/ vendas & PPE/vendas & EBIT/ativos \\
\hline Tratadas $(\mathrm{n}=76)$ & 13,88 & 0,23 & 0,04 & 0,11 & 0,81 & 0,08 \\
\hline Controle $(\mathrm{n}=76)$ & 14,53 & 0,23 & 0,05 & 0,12 & 0,81 & 0,07 \\
\hline Diferença & $-0,65$ & 0,00 & $-0,01$ & $-0,01$ & 0,00 & 0,01 \\
\hline Valor-p da estatística $x^{2}$ de Pearson & 0,42 & 0,87 & 0,63 & 0,87 & 0,87 & 0,63 \\
\hline
\end{tabular}

Nota: Medianas para as firmas tratadas e controle em 2007. As firmas tratadas são definidas como firmas dos segmentos Regular e Nível 1 na Bz. As firmas controle são definidas como firmas dos segmentos Nível 2 e Novo Mercado. A amostra é composta de 76 firmas tratadas e 76 não tratadas. 0 teste para uma diferença nas medianas de uma característica de firma entre os dois grupos é realizado calculando-se a estatística $x^{2}$ de Pearson, com os valores-p desse teste apresentados na última linha de cada coluna.

As inferências sobre o efeito do IFRS no valuation ( $Q$ de Tobin e razão entre valor de mercado e valor patrimonial) baseiam-se em diferenças nos resultados pós-tratamento dos grupos tratado e controle. Utilizamos a seguinte especificação:

$$
\text { Valor }_{i, t}=\omega\left(\text { BaixaGov }_{i} \times \text { Pós }_{t}\right)+\tau \text { Pós }_{t}+\varphi \text { BaixaGov }_{i}+\beta^{\prime} X_{i, t}+\varepsilon_{i, t}
$$

onde:

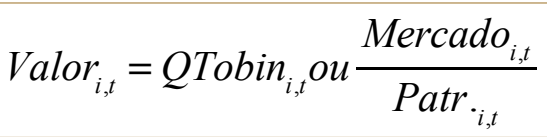

BaixaGov é uma variável dummy para as firmas tratadas (firmas dos níveis mais baixos de governança) e Pós ${ }_{t}$ é uma variável dummy temporal igual a o para 2007 e 1 para 2010. Em especificações alternativas, utilizamos dados de anos diferentes, e Pós $s_{t}$ i igual o ou 1 para anos diferentes.

$X_{i, t}$ é uma matriz de variáveis controle pré-adoção (tamanho, alavancagem, receitas líquidas/ativos, EBIT/ativos, EBIT/vendas, PPE/vendas e setor NAICS); e $\omega, \tau$, $\varphi$, e $\beta$ ' são parâmetros a ser estimados. Nosso principal coeficiente de interesse é $\omega$, e nos referimos a ele como ATT (average treatment on the treated - efeito médio do tratamento na firma tratada).

Em todas as regressões, os erros padrão estão agrupados em nível de firma, e são robustos para heterocedasticidade.

\section{RESULTADOS}

O Painel A da Tabela 5 apresenta nossas estimativas dos efeitos médios da adoção do IFRS nas firmas tratadas (ATT), indicados pelo coeficiente $\omega$ na equação 1 . Nossa estimativa mostra que o efeito ATT da adoção obrigatória do IFRS é um aumento de 0,301 no Q de Tobin, estatisticamente significativo no nível de $5 \%$. Esse efeito é economicamente significativo, pois corresponde a aproximadamente $20 \%$ do valor médio do $Q$ de Tobin antes do choque. Também estimamos um efeito ATT positivo de 0,226 na razão entre valor de mercado e valor patrimonial, equivalente a quase $20 \%$ dos níveis médios preexistentes de razão entre valor de mercado e valor patrimonial; esse resultado é estatisticamente significativo no nível de $10 \%$. Esses resultados estão no centro de nossa análise dos efeitos das práticas contábeis no valor da firma. Como nosso procedimento de pareamento garante que nossos grupos tratado e de controle são semelhantes, afirmamos ter encontrado uma relação causal.

Como algumas características do IFRS foram adotadas já em 2008, também verificamos o efeito imediato da adoção, comparando as mudanças em nossas variáveis de interesse para as firmas tratadas e controle entre 2007 e 2008. Nossas estimativas de ATT, apresentadas na terceira e quarta colunas do Painel A, são apenas um pouco menores do que nossas estimativas anteriores.

Os resultados para nossas variáveis controle são consistentes com a literatura anterior: firmas com maior receita líquida têm maior probabilidade de ter um $Q$ de Tobin e razão entre valor de mercado e valor patrimonial mais elevados, conforme esperado. Além disso, encontramos uma relação negativa entre valor da firma e tamanho, EBIT/vendas, crescimento de vendas e PPE/vendas.

Testamos um possível efeito de previsão, definindo a variável dummy de pós-tratamento como 1 em 2007 e o em 2006 (duas primeiras colunas), para verificar se os investidores preveem os benefícios do IFRS para o valuation da firma antes da sua adoção. Os resultados apresentados no Painel B da Tabela 5 mostram que mais da metade do efeito no $Q$ de Tobin e quase todo o efeito na razão entre valor de mercado e valor patrimonial ocorreram já em 2007, antes mesmo de as firmas nos baixos níveis governança adotarem o IFRS. Na terceira e quarta colunas, 
ARTIGOS | ADOÇÃO OBRIGATÓRIA DE IFRS, GOVERNANÇA CORPORATIVA E VALOR DA FIRMA

Joelson Sampaio | Humberto Gallucci | Vinicius Augusto Brunassi Silva | Rafael Felipe Schiozer

utilizamos dados de 2007 (pré-tratamento) e 2008 (pós-tratamento) e constatamos que os ATTs são positivos, mas não estatisticamente significativos nos níveis usuais. 0 fato de observarmos um efeito de previsão exclui a possível explicação alternativa de que as diferenças pré-existentes entre o valuation das firmas nos níveis mais altos e mais baixos de governança se deviam simplesmente a diferentes procedimentos contábeis (IFRS versus BRGAAP).

Tabela 5. Testes de diferença-nas-diferenças - Q de Tobin e mercado-patrimonial

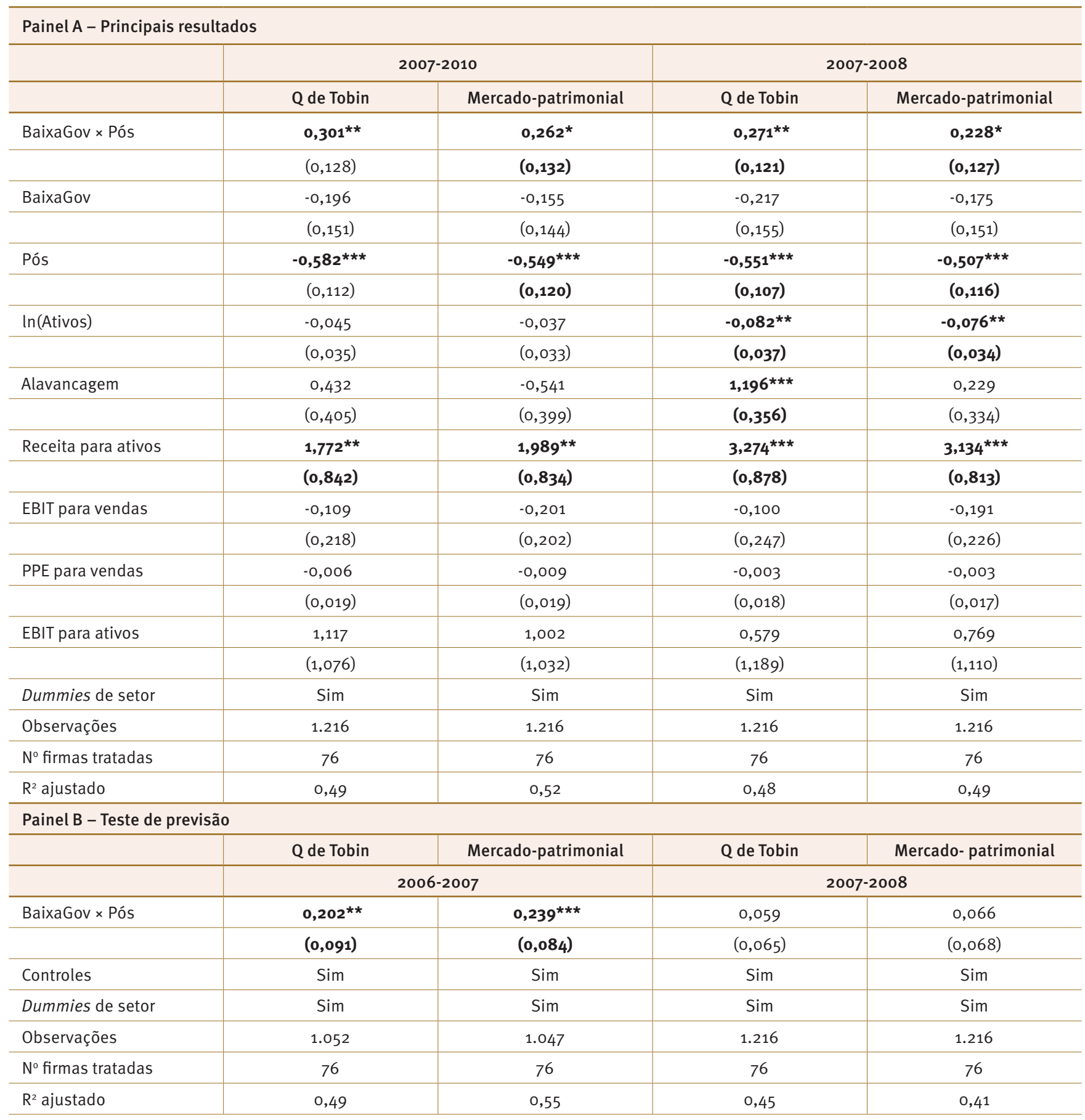

Nota: Esta tabela apresenta a diferença-nas-diferenças do Q de Tobin e da razão entre valor de mercado e valor patrimonial das firmas antes e depois da adoção obrigatória do IFRS nas firmas brasileiras. As variáveis de controle são: In(Ativos), Alavancagem, Receita para ativos, EBIT para vendas, PPE para vendas e EBIT para ativos. Os símbolos *, ** $\mathrm{e}^{* * *}$ indicam significância estatística em 10\%, $5 \%$ e $1 \%$, respectivamente. 
Os resultados combinados dos painéis A e B da Tabela 5 sugerem que os investidores previram os efeitos positivos do IFRS no valor da firma, o que pode ter ocorrido por várias razões. A redução na probabilidade de expropriação pelos acionistas controladores, dadas as regras de disclosure mais rigorosas do IFRS, ou simplesmente mais transparência para os investidores estrangeiros (voltaremos a este ponto na próxima seção), são explicações plausíveis.

Também realizamos uma série de testes placebo, utilizando diferentes janelas de tempo para o nosso tratamento e datas alternativas para parear as firmas tratadas e controle. Nossas estimativas de ATT não são estatisticamente significativas em nenhum desses testes placebo, o que sugere que nossos resultados não são determinados por características não observáveis que determinassem simultaneamente a escolha da firma quanto ao nível de governança corporativa e valuation.

\section{CANAIS QUE REDUZEM A DIFERENÇA DE VALUATION E TESTES DE ROBUSTEZ}

\section{Participação estrangeira no capital acionário e liquidez das ações}

Comparamos a participação de investidores estrangeiros nos dois grupos de firmas. Seguimos Colombo e Caldeira (2018) e coletamos manualmente a estrutura acionária da CVM. Os dados trazem informações sobre a participação de investidores com participação igual ou superior a $5 \%$ em cada classe de ações emitidas. Utilizamos essas informações para calcular a proporção de participação de investidores estrangeiros para cada classe de ações de cada firma em cada ano.

Realizamos a regressão na Equação (1), utilizando a proporção de participação de investidores estrangeiros como nossa variável dependente. Os resultados são apresentados no Painel A da Tabela 6. Nossas estimativas indicam que a participação estrangeira nas ações ordinárias (com direito a voto) das firmas tratadas em relação às firmas controle aumenta em aproximadamente 19,3 pontos percentuais entre 2007 e 2010, o que é estatisticamente significativo no nível de $10 \%$. Na primeira linha da coluna 2 , utilizamos a participação estrangeira em todas as ações (com e sem direito a voto), em vez de apenas ações com direito a voto, e o efeito é um pouco menor (16,3 pontos percentuais). Conforme mostrado na Tabela 6, Painel C, as firmas não tratadas apresentavam maior participação estrangeira do que as firmas tratadas em 2007: 16 pontos percentuais em ações ordinárias e 14 pontos percentuais no total de ações. Também avaliamos o efeito imediato da adoção do IFRS, comparando a mudança na participação estrangeira para firmas tratadas e controle, entre 2007 e 2008. Nossas estimativas, relatadas na segunda coluna do Painel A, são um pouco menores do que nossas estimativas anteriores. A adoção do IFRS para firmas nos níveis mais baixos de governança está associada a um aumento de aproximadamente 13,9 pontos percentuais na participação estrangeira total no capital acionário (estatisticamente significativo no nível de 10\%). O coeficiente para a participação estrangeira em ações ordinárias é estatisticamente insignificante, mas sua magnitude é comparável com os outros coeficientes do Painel A da Tabela 6.

Nossos resultados indicam que a redução na diferença de valuation entre firmas nos níveis mais baixos e mais altos de governança corporativa após a adoção obrigatória do IFRS pode ser, pelo menos em parte, devida a um aumento na demanda dos investidores estrangeiros por firmas nos níveis mais baixos de governança corporativa. A convergência contábil permite que investidores estrangeiros melhorem o monitoramento da firma, mitigando a expropriação por acionistas controladores. Essa evidência também é consistente com a diferença de valuation pré-IFRS entre firmas tratadas e não tratadas, e explica por que as firmas nos níveis mais baixos de governança se auto selecionaram para a não adoção do IFRS antes de 2008.

Para investigar melhor os canais que reduzem a diferença de valuation, analisamos a liquidez das ações. Este não é necessariamente um canal separado da participação estrangeira; na verdade, é plausível que o aumento da participação estrangeira melhore a liquidez das ações. Calculamos três medidas de liquidez diferentes para avaliar as melhorias nas negociações de mercado devidas à adoção do IFRS. Primeiro, utilizamos a medida de Chung e Zhang (2014) para obter o spread de fechamento percentual da ação i no dia d. A medida é especificada da seguinte forma:

$$
\text { Spread }_{i, q}=\frac{1}{D} \sum_{d=1}^{D} \frac{A s k_{i, d}-\text { Bid }_{i, d}}{M_{i, d}}
$$

onde $A s k_{i, d}$ é o preço de venda de fechamento da ação $i$ no dia $d, B i d_{i, d}$ é o preço de compra de fechamento da ação $i$ no dia $d, M_{i, d}$ é a média de $A s k_{i, d}$ e $B i d_{i, d}$ por trimestre, e $D$ é o número de dias em um trimestre, conforme relatado pelo Capital IQ. Para ações de duas classes, utilizamos a mais líquida. 0 spread de fechamento percentual é a melhor proxy de spread para capturar variações nos spreads efetivo e cotado (Fong, Holden, e Trzcinka, 2017). 
ARTIGOS | ADOÇÃO OBRIGATÓRIA DE IFRS, GOVERNANÇA CORPORATIVA E VALOR DA FIRMA

Joelson Sampaio | Humberto Gallucci | Vinicius Augusto Brunassi Silva | Rafael Felipe Schiozer

Tabela 6. Testes de diferença-nas-diferenças - Investimento estrangeiro, liquidez e diferenças medias entre as firmas tratadas e controle

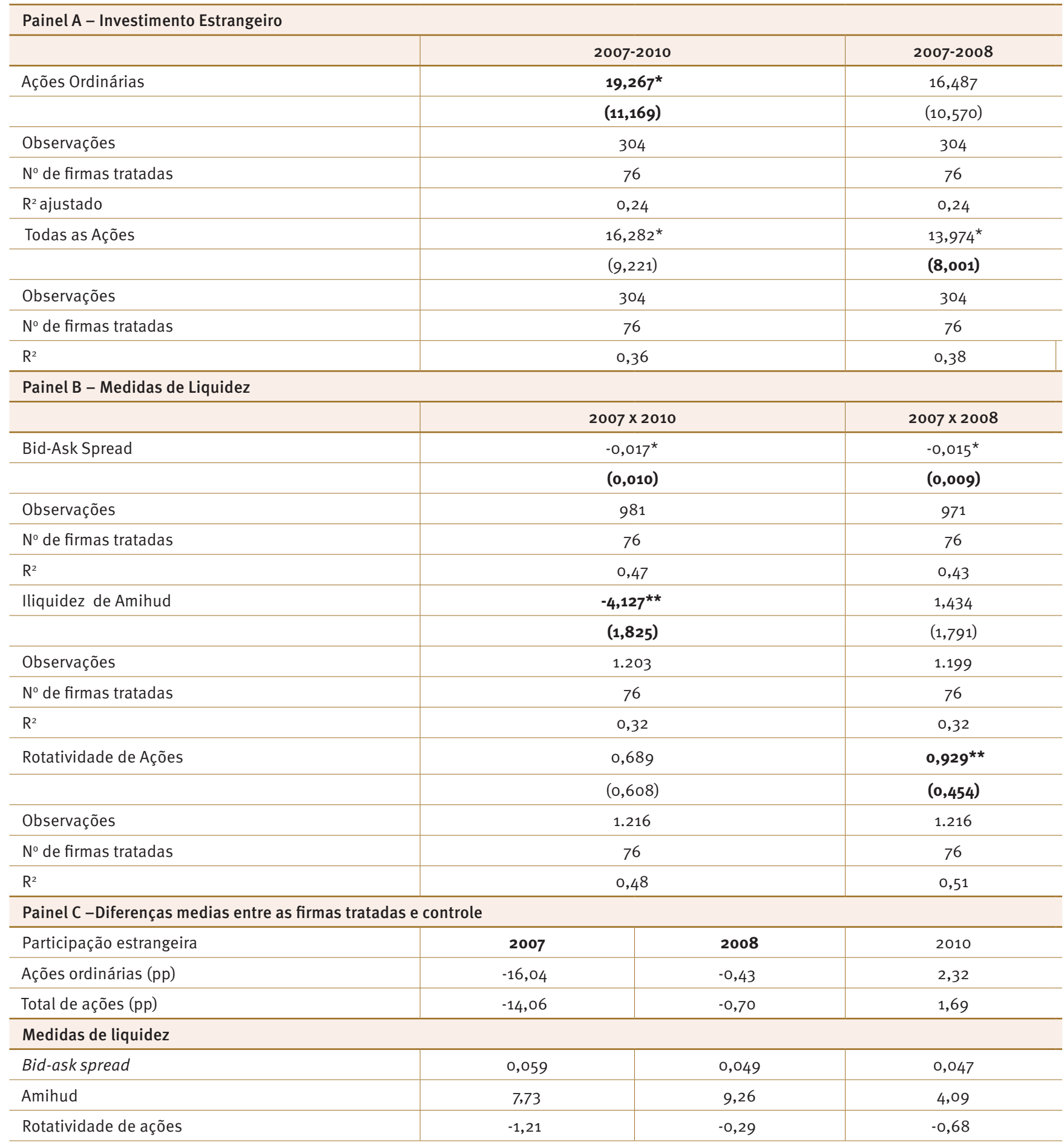

Nota: O painel A apresenta a diferença-nas-diferenças do percentual de investidores estrangeiros das firmas (ações ordinárias e total de ações) para cada ano. O painel B apresenta a diferença-nas-diferenças das firmas, considerando as medidas de liquidez (Bid-Ask Spread, iliquidez de Amihud e rotatividade de ações). As variáveis de controle são: In(Ativos), Alavancagem, Receitas para ativos, EBIT para vendas, PPE para vendas e EBIT para ativos. O painel C apresenta a diferença média para firmas tratadas e controle para cada ano (firmas tratadas menos controle). As variáveis para investidores estrangeiros são anuais. As medidas de liquidez são a média das variáveis trimestrais originais para cada ano. Diferença entre firmas tratadas e controle. A variável Amihud é multiplicada por 1.00o.0oo. Os símbolos *, ** e *** indicam significância estatística em $10 \%, 5 \%$ e $1 \%$, respectivamente. 
Em segundo lugar, seguimos Amihud (2002) e medimos a iliquidez das ações como a variação percentual absoluta do preço por dólar do volume negociado diário. Essa razão mede diretamente o impacto de uma unidade monetária de volume negociado nos retornos das ações. A taxa de iliquidez de Amihud (2002) é definida da seguinte forma:

$$
V_{i, t}=\sum_{d=1}^{D_{i, t}} \frac{\left|R_{i, d, t}\right| / V_{i, d, t}}{D_{i, t}}
$$

onde $R_{i, d, t}$ e $V_{i, d, t}$ são, respectivamente, o retorno e o volume monetário negociado da ação $i$ no dia $d$ no trimestre $t$, e $D_{i, t}$ é o número de dias em que a ação $i$ é negociada em um trimestre.

Por fim, calculamos a razão de rotatividade, que captura o período médio de detenção das ações (Atkins \& Dyl, 1997). Ela é definida como a razão entre o número de ações negociadas e o número de ações em circulação, e é calculada da seguinte forma:

$$
\text { Rotatividade }_{i, t}=\sum_{d=1}^{D_{i, t}} \frac{\operatorname{Vol}_{i, d, t} / A c ̧ \tilde{a} o_{i, d, t}}{D_{i, t}}
$$

onde $V o l_{i, d, q}$ é o volume negociado para a ação i no dia d do trimestre t, $A c ̧ a \tilde{a} o_{i, d, t}$ é o número de ações em circulação para a ação $i$ no dia $d$ do trimestre $t$, e $D_{i, t}$ é o número de dias de negociação para a ação $i$ no trimestre $t$.

O Painel B da Tabela 6 apresenta os resultados da estimativa da Equação (1), utilizando essas três medidas de liquidez como nossa variável dependente. 0 primeiro coeficiente da primeira linha indica que o bid-ask spread das firmas nos níveis mais baixos de governança diminui em aproximadamente 1,7 ponto percentual em comparação com as firmas nos níveis mais altos de governança após a adoção do IFRS (estatisticamente significativo no nível de 10\%). A maior parte desse efeito ocorre imediatamente em 2008, como mostra o coeficiente de -0,015. Na segunda linha do Painel B da Tabela 6, apresentamos os resultados da medida de iliquidez de Amihud (2002) (Eq. 4), que indica que a diferença de liquidez entre as ações das firmas nos níveis baixos e altos de governança diminui após a adoção do IFRS (estatisticamente significativa ao nível de $5 \%$ ). No entanto, a regressão para a mudança diferencial nessa medida entre 2007 e 2008 produz resultados estatisticamente insignificantes.

Finalmente, a última linha do Painel B da Tabela 6 mostra os resultados da regressão, utilizando a rotatividade das ações (Eq. 5) como variável dependente. Os coeficientes são positivos, como esperado, mas o ATT entre 2007 e 2010 é estatisticamente insignificante nos níveis usuais, enquanto o ATT entre 2007 e 2008 é estatisticamente significativo no nível de $5 \%$.

Tomados em conjunto, os resultados da Tabela 6 confirmam que o declínio da diferença de valuation entre as firmas nos níveis baixos e altos de governança após a adoção do IFRS é pelo menos parcialmente explicado por uma redução na diferença da participação estrangeira e da liquidez das ações entre os dois grupos de firmas.

\section{Outros testes de robustez}

Uma preocupação é que as firmas nos níveis altos de governança sejam mais sensíveis a uma crise financeira, devido a características omitidas da firma, como maior exposição operacional ou financeira aos ciclos econômicos globais do que as firmas nos níveis baixos de governança. Afirmamos que isso é implausível por vários motivos. Primeiro, o pareamento de setor captura a maior parte da sensibilidade aos ciclos de negócios. Segundo, para descartar a preocupação de que as firmas nos níveis baixos e altos de governança possam ter diferentes sensibilidades à crise, realizamos uma série de regressões de diferença em diferenças (DD), nas quais utilizamos covariáveis operacionais e financeiras como variáveis dependentes. A lógica por trás desses testes é que, se alguma característica não observada da firma fizer com que as firmas tratadas e controle sejam afetadas de forma heterogênea pela crise, devemos observar diferentes mudanças nas métricas de desempenho operacional e financeiro durante o período da crise. Mais especificamente, estimamos a seguinte regressão:

$$
Y_{i, t}=y\left(\text { BaixaGov }_{i} \times \text { Pós }_{t}\right)+\delta_{1} \text { BaixaGov }_{i}+\beta^{\prime} X_{i, t}+\varepsilon_{i, t}
$$

onde:

$Y_{i, t}$ é uma das seguintes variáveis: tamanho, alavancagem, receita líquida/ativos, EBIT/ativos, EBIT/vendas, ou PPE/vendas.

BaixaGov $_{i t}$, Pós ${ }_{t}$, e $X_{i t}$ são previamente definidas, e $\gamma, \delta_{1}, \delta_{2}$, e $\beta$ são coeficientes a ser estimados.

Nosso principal parâmetro de interesse na regressão é $\gamma$. Um $\gamma$ não significativo indica que, para essa variável dependente
Y específica, o efeito do tratamento é homogêneo entre as firmas tratadas e de controle. Os resultados da Tabela 7 apresentam o coeficiente $\gamma$ para as regressões estimadas com cada uma das variáveis dependentes. Por exemplo, a variável dependente na primeira linha da Tabela 7 é $\ln$ (ativos). Na segunda linha, é a razão de alavancagem, e assim por diante. A diferença entre a primeira e a segunda colunas da Tabela 7 é que a primeira coluna 
utiliza dados dos quatro trimestres de 2007 e 2010, enquanto a segunda coluna utiliza dados de 2007 e 2008 (e Pós é ajustada de acordo). Nenhum dos coeficientes apresentados na Tabela 7 é estatisticamente significativo, sugerindo fortemente que as firmas tratadas e controle não possuem sensibilidades diferentes à crise financeira, em média.

\section{Tabela 7. Testes de robustez - mudança nas covariáveis}

\begin{tabular}{|c|c|c|c|c|c|c|c|c|c|c|c|c|}
\hline & \multicolumn{2}{|c|}{ In(Ativos) } & \multicolumn{2}{|c|}{ Alavancagem } & \multicolumn{2}{|c|}{ Receitas/ativos } & \multicolumn{2}{|c|}{ EBIT/vendas } & \multicolumn{2}{|c|}{ PPE/vendas } & \multicolumn{2}{|c|}{ EBIT/ativos } \\
\hline Coeficiente & $-0,144$ & $-0,082$ & $-0,064$ & $-0,033$ & 0,001 & $-0,003$ & 0,029 & $-0,005$ & $-0,085$ & 0,108 & $-0,012$ & $-0,001$ \\
\hline Erro padrão & $(0,117)$ & $(0,092)$ & $(0,047)$ & $(0,039)$ & $(0,010)$ & $(0,005)$ & $(0,031)$ & $(0,031)$ & $(0,254)$ & $(0,308)$ & $(0,009)$ & $(0,006)$ \\
\hline Observações & 1.216 & 1.216 & 1.216 & 1.216 & 1.216 & 1.216 & 1.216 & 1.216 & 1.216 & 1.216 & 1.216 & 1.216 \\
\hline R2 & 0,69 & 0,71 & 0,45 & 0,52 & 0,66 & 0,65 & 0,73 & 0,74 & 0,73 & 0,68 & 0,80 & 0,80 \\
\hline
\end{tabular}

Nota: Esta tabela apresenta a diferença-nas-diferenças das covariáveis antes e depois da adoção obrigatória do IFRS nas firmas brasileiras.

Outro fator de confusão é a possibilidade de que as diferentes mudanças no valuation da firma nos grupos tratado e controle advenham de suas diferentes sensibilidades à taxa de câmbio. Como o real brasileiro valorizou-se em aproximadamente $25 \%$ do final de 2007 até o terceiro trimestre de 2008 , poderia haver a preocupação de que as firmas nos níveis altos governança tenham sido mais afetadas por essa valorização do que as firmas nos níveis baixos. Afirmamos que os resultados de nossas regressões reportadas na Tabela 7 ajudam a eliminar essa preocupação, porque qualquer diferença desse tipo na exposição cambial apareceria na receita ou no EBIT da firma nessas regressões. No entanto, para mitigar ainda mais essa preocupação, utilizamos a depreciação do real em 2015 (quando não houve alteração nas exigências contábeis) como experimento. Dividimos nossa amostra em $\mathrm{Q}$ de Tobin baixo (abaixo da mediana) e alto (acima da mediana), a partir de dezembro de 2014, e testamos se seu valuation foi afetado de forma diferente pela depreciação do real. 0 Gráfico 3 mostra que o Q de Tobin médio dos dois grupos segue tendências aproximadamente paralelas ao longo de todo o período, de 2014 a 2016, indicando que as firmas com Q de Tobin alto e baixo estão igualmente expostas à taxa de câmbio, em média.

Outra preocupação pode ser que as firmas não tratadas selecionadas para servir como pares (controle) tenham características especiais que causem viés de seleção, ou que o procedimento de pareamento atribua "artificialmente" um peso excessivo a firmas controle específicas que aparecem mais de uma vez como par para firmas tratadas. Para mitigar essa preocupação, realizamos uma série de regressões de diferenças em diferenças sem pareamento. Os coeficientes de interesse (não apresentados para economizar espaço) têm a mesma ordem de grandeza que os da Tabela 5, e permanecem econômica e estatisticamente significativos.

\section{Gráfico 3. Teste de robustez - Q de Tobin mediano e choque cambial}

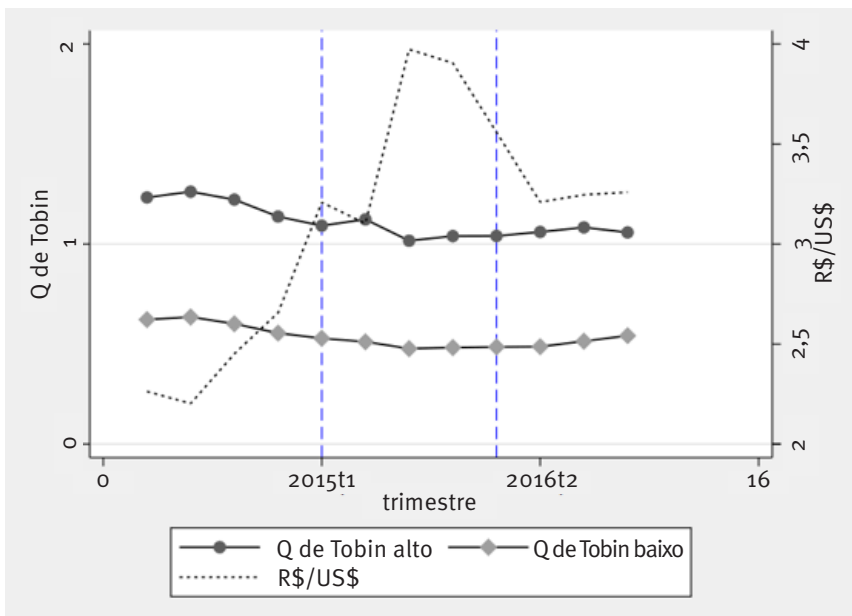

Nota: Este gráfico apresenta o resultado de uma amostra dividida em firmas com Q de Tobin alto e baixo durante a depreciação da taxa de câmbio brasileira em 2015.

Finalmente, realizamos vários testes de robustez aqui não relatados para economizar espaço, tais como mudanças no procedimento de pareamento e covariáveis, e a execução de regressões com e sem variáveis de controle macroeconômicas e em nível de firma. Nossas inferências são mantidas em todos esses testes de robustez.

\section{CONCLUSÃO}

Este estudo investiga se a transparência contábil afeta o valuation da firma. O foco no Brasil durante a adoção obrigatória do IFRS entre 2008 e 2010 nos permite mitigar as preocupações de endogeneidade 
presentes em estudos entre países, e, ao mesmo tempo, aproveitar a heterogeneidade ex-ante de qualidade contábil e governança corporativa das firmas brasileiras. As particularidades institucionais do mercado brasileiro, como o baixo nível de aplicação da lei e a abordagem formalista do BRGAAP preexistente, resultam em um maior nível de melhoria da transparência contábil após a adoção do IFRS em comparação com as economias desenvolvidas.

Utilizamos uma técnica de pareamento que nos permite comparar o valuation das firmas entre as empresas listadas nos níveis mais baixos de governança corporativa da Bolsa de Valores de São Paulo, que tiveram de adotar o IFRS em 2008, e outras firmas semelhantes listadas nos níveis mais altos de governança corporativa da bolsa, que já haviam adotado o IFRS antes que ele se tornasse obrigatório. Nossos resultados indicam que a melhor transparência proporcionada pela adoção do IFRS aumenta o $Q$ de Tobin em até 30 pontos percentuais e a razão entre valor de mercado e valor patrimonial em 26 pontos percentuais, praticamente eliminando a diferença de valuation preexistente entre as firmas listadas nos níveis altos e baixos de governança corporativa. Também apresentamos dois canais que levam à redução da diferença de valuation: a redução da diferença em participação estrangeira no capital acionário e em liquidez das ações. Reconhecemos, no entanto, que, dada a magnitude muito grande do efeito da adoção do IFRS no valor da firma (30 pontos percentuais no Q de Tobin), pode haver outros canais atuando conjuntamente.

Nossos resultados somam-se a evidências anteriores de que a transparência melhora o valor da firma. Enquanto a maioria dos estudos anteriores se baseia na heterogeneidade da transparência entre países, nossa estratégia de identificação, que utiliza um experimento quase natural e técnicas de pareamento, permite identificar melhor a relação causal entre qualidade contábil e valor da firma. Nossas inferências lançam luz sobre o papel da regulamentação na oferta de transparência para proteger os acionistas minoritários. Embora nosso estudo não investigue diretamente os motivos que determinaram a diferença de valuation pré-IFRS entre firmas nos níveis altos e baixos de governança, pesquisas anteriores mostram que essa diferença preexistente pode ser devida à expropriação entre acionistas controladores e acionistas minoritários. Como a decisão de não adotar o IFRS até que fosse exigido por lei foi essencialmente uma escolha dos gestores e acionistas controladores, especulamos que essa decisão pode ter sido motivada por esses atores extraírem benefícios privados da transparência reduzida. Portanto, nossos resultados sugerem que a melhoria da qualidade contábil mitiga a expropriação e, portanto, melhora o retorno para os acionistas minoritários.

A expropriação dos acionistas minoritários pelos acionistas controladores é particularmente relevante nos mercados emergentes, onde a propriedade acionária tende a ser mais concentrada, as ações sem direito a voto são mais comuns, e a proteção ao investidor tende a ser menor do que nos mercados desenvolvidos. Para garantir um ambiente de investimentos saudável, os reguladores devem se concentrar na melhoria da qualidade contábil e na aplicação das regras de transparência.

\section{REFERÊNCIAS}

Admati, A., \& Pfleiderer, P. (1988). A theory of intraday trading patterns: Volume and price variability. Review of Financial Studies, 1, 3-40.doi: 10.1093/rfs/1.1.3

Almeida, H., Campello, M., Laranjeira, B., \& Weisbenner, S. (2011). Corporate debt maturity and the real effects of the 2007 credit crisis. Critical Financial Review, 1, 3-58.doi: 10.3386/w14990

Amihud, Y. (2002). Illiquidity and stock returns: Cross-section and timeseries effects. Journal of Financial Markets, 5(1), 31-56. doi: 10.1016/ S1386-4181(01)00024-6

Amiram, D. (2012). Financial information globalization and foreign investment decisions. Journal of International Accounting Research, 11, 57-81.doi: 10.2308/jiar-50282

Angrist, J. D., \& Pischke, J.-S. (2008). Mostly harmless econometrics: An empiricist's companion. Princeton, NJ: Princeton University Press,1ed.

Armstrong, C. S., Barth, M. E., \& Riedl, E. J. (2010). Market reaction to the adoption of IFRS in Europe. The Accounting Review, 85(1), 31-61.doi: 10.2308/accr.2010.85.1.31

Atkins, A. B., \& Dyl, E. A. (1997). Transactions costs and holding periods for common stocks. Journal of Finance, 52(1), 309-325.doi: 10.1111/ j.1540-6261.1997.tb03817.x

Baiman, S., \& Verrecchia, R. (1996). The relation among capital markets, financial disclosure, production efficiency, and insider trading. Journal of Accounting Research, 34, 1-22. Doi: http://hdl.handle. net/10.2307/2491329

Ball, R. (2006). International Financial Reporting Standards (IFRS): Pros and cons for investors. Accounting and Business Research, 36(1), 5-27.doi: 10.1080/00014788.2006.9730040

Ball, R., Kothari, S.P., \& Robin, A. (2000). The effect of international institutional factors on properties of accounting earnings. Journal of Accounting \& Economics, 29, 1-51. doi: 10.1016/S0165 4101(00)00012-4

Ball, R., Robin, A., \& Wu, J. (2003). Incentives versus standards: Properties of accounting income in four East Asian countries. Journal of Accounting \& Economics, 36, 235-270. doi: 10.1016/j. jacceco.2003.10.003

Barth, M. E., Konchitchki, Y., \& Landsman, W. R. (2013). Cost of capital and financial statement transparency. Journal of Accounting and Economics, 55, 206-224. doi: 10.1016/j.jacceco.2013.01.004

Beatty, A., Chamberlain, S., \& Magliolo, J. (1996). An empirical analysis of the economic implications of fair value accounting for investment securities. Journal of Accounting and Economics, 22, 43-77. doi: 10.1016/S0165-4101(96)00429-6

Black, B. S., \& Carvalho, A. G. de. (2010). Corporate governance in Brazil. Emerging Markets Review, 11(11), 21-38.doi: 10.1016/j. ememar.2009.09.004

Black, B. S., Carvalho, A. G. de, Khanna, V., Kim, W., \& Yurtoglu, B. (2017) Corporate governance indices and construct validity. Corporate Governance-An International Review, 25, 397-410.

Black, B. S., Carvalho, A. G. de, \& Sampaio, J. O. (2014). The evolution of corporate governance in Brazil. Emerging Markets Review, 20, 176195. doi: 10.1111/corg.12215 
Botosan, C., \& Plumlee, M. (2002). A re-examination of disclosure level and the expected cost of equity capital. Journal of Accounting Research, 40, 21-40. doi: 10.1111/1475-679X.00037

Charitou, A., Karamanou, I., \& Kopita, A. (2018). Are analyst stock recommendation revisions more informative in the post-IFRS period? Journal of Business, Finance \& Accounting, 45(1), 115-139. doi: $10.1111 / \mathrm{jbfa}$

Charoenwong, C., Chong, B. S., \& Yang, Y. C. (2014). Asset liquidity and stock liquidity: International evidence. Journal of Business Finance \& Accounting, 43(3), 435-468. doi: 10.1111/jbfa.12052

Chung, K. H., \& Zhang, H. (2014). A simple approximation of intraday spreads using daily data. Journal of Financial Markets, 17, 97-120. doi: $10.2139 /$ ssrn.1346363

Coffee, J. (1984). Market failure and the economic case for a mandatory disclosure system. Virginia Law Review, 70, 717-753. doi: $10.2307 / 1073083$

Colombo, J. A., \& Caldeira, J. F. (2018). The role of taxes and the interdependence among corporate financial policies: Evidence from a natural experiment. Journal of Corporate Finance, 50, 402-423. doi: 10.1016/j.jcorpfin.2017.09.007

Daske, H., Hail, L., Leuz, C., \& Verdi, R. (2008). Mandatory IFRS reporting around the world: Early evidence on the economic consequences. Journal of Accounting Research, 46, 1085-1142.doi: https://doi. org/10.1111/j.1475-679X.2008.00306.x

Daske, H., Hail, L., Leuz, C., \& Verdi, R. S. (2013). Adopting a label: Heterogeneity in the economic consequences of IFRS adoptions. Journal of Accounting Research, 53, 970-1080.doi: 10.1111/1475 679X.12005

Diamond, D., \& Verrecchia, R. (1991). Disclosure, liquidity, and the cost of capital. Journal of Finance, 46, 1325-1360. doi: 10.1111/j.15406261.1991.tbo4620

Dye, R. (1990). Mandatory versus voluntary disclosures: The cases of financial and real externalities. The Accounting Review, 65, 1-24. doi: $10.2139 /$ ssrn.2010326

Durnev, A., \& Kim, E. H. (2005). To steal or not to steal: Firm attributes, legal environment, and valuation. Journal of Finance, 60, 1461-1493. doi: 10.1111/j.1540-6261.2005.00767.x

Figlioli, B., Lemes, S., \& Lima, F. G. (2017). IFRS, synchronicity, and financial crisis: The dynamics of accounting information for the Brazilian capital market. Revista de Contabilidade e Finanças, 28(75), 326-343. doi: 10.1590/1808-057×201704450

Fong, K. Y., Holden, C. W., \& Trzcinka, C. A. (2017). What are the best liquidity proxies for global research? Review of Finance, 21(5), 13551401. doi: $10.1093 / \mathrm{rof} / \mathrm{rfxo03}$

George, E. T. De, Li, X., \& Shivakumar, L. (2016). A review of the IFRS adoption literature. Review of Accounting Studies, 21, 898-1004. doi: 10.2139/ssrn.2664475

Jeanjean, T., \& Stolowy, H. (2008). Do accounting standards matter? An exploratory analysis of earnings management before and after IFRS adoption. Journal of Accounting and Public Policy, 27(6), 480-494. doi: 10.12691/jfa-3-3-3

Kanodia, C. (2006). Accounting disclosure and real effects. Foundations and Trends in Accounting, 1(3), 167-258. doi: 10.1561/1400000003
Karamanou, I., \& Nishiotis, G. (2005). The valuation effects of firm voluntary adoption of International Accounting Standards [Working Paper]. University of Cyprus. doi: 10.2139/ssrn.676328

Klapper, L. F., \& Love, I. (2004). Corporate governance, investor protection and performance in emerging markets. Journal of Corporate Finance, 10, 703-728. doi: 10.1016/So929-1199(03)00046-4

KPMG. (2008). Brazil and International Financial Reporting Standards, First-time adoption of IFRS: Answers to frequently asked questions. Retrieved from http://www.kpmg.com.br/publicacoes/audit/IFRS/ Folder_IFRS_Perguntas_Respostas_ingles_2506.pdf

Lambert, R., Leuz, C., \& Verrecchia, R. (2007). Accounting information, disclosure, and the cost of capital. Journal of Accounting Research, 45, 385-420. doi: 10.1111/j.1475-679X.2007.00238.x

Lepone, A., \& Wong, J. B. (2018). The impact of mandatory IFRS reporting on institutional trading costs: Evidence from Australia. Journal of Business Finance \& Accounting, 45(3), 797-817. doi: 10.1111/ jbfa.12320

Leuz, C., \& Verrecchia, R. E. (2001). The economic consequences of increased disclosure. Journal of Accounting Research, 38, 91-124. doi: $10.2307 / 2672910$

Nenova, T. (2003). The value of corporate voting rights and control: A cross-country analysis. Journal of Financial Economics, 68, 325-351. doi: 10.1016/S0304-405X(03)00069-2

Pelucio-Grecco, M. C., Geron, C. M. S., Grecco, G. B., \& Lima, J. P. C. (2014). The effect of IFRS on earnings management in Brazilian nonfinancial public companies. Emerging Markets Review, 21, 42-66. doi: 10.1016/j.ememar.2014.07.001

Roberts, M., \& Whited, T. M. (2013). Endogeneity in empirical corporate finance. Handbook of the Economics of Finance, v.2, Ch. 7 (pp. 493 572), Amsterdam: Elsevier Publishing. doi: 10.1016/B978-0-44453594-8.00007-0

Rodrigues, L. L., Schmidt, P., \& Dos-Santos, J. L. (2012). The origins of modern accounting in Brazil: Influences leading to the adoption of IFRS. Research in Accounting Regulation, 24, 15-24. doi: 10.1016/j. racreg.2011.12.003

Santos, E. S., Schiozer, R. F., \& Ponte, V. M. R. (2019). Disclosure under IFRS: Does the legal origin disclosure gap persist for cross-listed firms? [Working Paper]. Retrieved from https://papers.ssrn.com/ sol3/papers.cfm?abstract_id $=2956918$

Silveira, A. D. M., \& Barros, L. A. B. C. (2008). Determinantes da qualidade da governança corporativa das companhias abertas brasileiras, Revista Eletrônica de Administração, 14(3), 512-540.

Silveira, A. D. M., Barros, L. A. B. C., \& Famá, R. (2003). Estrutura de governança e valor das companhias abertas brasileiras. Revista de Administração de Empresas, 43(3), 50-64. doi: 10.1590/So03475902003000300005

Verrecchia, R. (2001). Essays on disclosure. Journal of Accounting \& Economics, 32, 91-180. doi: 10.1016/S0165-4101(01)00025-8

Verriest, A., Gaereminck, A., \& Thornton, D. B. (2012). Corporate governance and properties of IFRS adoption [Working Paper]. Retrieved from http://www.econtrack.nl/uploads/document/coporate\%2ogo vernance\%20and\%20properties\%200f\%20IFRS\%20Adoption.pdf

\section{CONTRIBUIÇÃO DOS AUTORES}

Os autores declaram que participaram de forma conjunta, desde a conceitualização e abordagem teórico-metodológica, revisão teórica (levantamento de literatura), coleta de dados (exceto o professor Rafael Felipe Schiozer), passando pela análise de dados, e, por fim, redação e revisão final. 